FINANCIANDO O SUS: ALGUMAS QUESTÕES PARA O DEBATE

\author{
FUNDING THE BRAZILIAN NATIONAL HEALTH SERVICE (SUS): \\ SOME ISSUES FOR THE DEBATE
}

Ruben Araujo de Mattos 1

Nilson do Rosário Costa 3

Resumo Este debate discute questões relacionadas ao financiamento do Sistema Único de Saúde (SUS). Na primeira parte, Ruben de Mattos defende a criação de dispositivos para a elevação progressiva dos gastos públicos em saúde. Segundo o debatedor, o maior desafio do governo será viabilizar - e sustentar - um sistema que garanta, de fato, o acesso universal e igualitário. Mattos também destaca a importância dos repasses federais entre os níveis de governos, por vê-los como instrumentos capazes de reduzir as desigualdades entre as regiões e incentivar políticas que contribuam para a consolidação do SUS. Na segunda parte, Nilson do Rosário afirma que o ajuste fiscal da década de 1990, conseqüência da política de estabilização monetária, limitou a capacidade de financiamento governamental na atenção à saúde, gerando efeitos perversos devido à ampliação da desigualdade social. A seguir, explica como o setor saúde respondeu às exigências de ajuste macroeconômico nas despesas públicas através de estratégias substitutivas, contexto em que o Programa de Saúde da Família (PSF) se expandiu rapidamente, tornando-se estratégico na agenda da ampliação da atenção ambulatorial básica do país.

Palavras-chave financiamento do Sistema Único de Saúde; gastos públicos em saúde; Programa de Saúde da Família (PSF).
Abstract This work discusses some of the issues related to the funding of the Brazilian National Health Service (SUS). In the first part of the paper, Ruben de Mattos advocates the creation of devices to guarantee a progressive increase in the public health budget. In the debater's view, the greatest challenge facing the government is the development - and the maintenance - of a system that can de facto guarantee universal and equalitarian access. Mattos also emphasizes the importance of the federal government's transfers of funds to local governments since the latter are seen as instrumental in the attempts to reduce inequality between regions and to encourage policies that will contribute to the SUS' consolidation. In the second part, Nilson do Rosário affirms that the 1990's fiscal adjustment, a consequence of the monetary stabilization policy, reduced the government's funding capacity with regard to health; due to the ensuing increase in social inequality, this had a series of adverse effects. Next, Mr. Rosário explains how the health sector responded to the demands for macroeconomic adjustment of public expenditure by means of substitutive strategies. It was in this context that the Family Health Programme (PSF) expanded rapidly, becoming a strategic item in the agenda for the expansion of basic outpatient care in this country.

Key words funding of the Brazilian National Health Service; public expenditure on health; Family Health Programme (PSF). 


\section{Financiando o SUS: algumas questões para o debate}

Em 1987, o Banco Mundial publicava um documento intitulado Financing health services: an agenda for reform (World Bank, 1987). Nele, criticavam-se os governos que concebiam a saúde como direito universal e buscavam oferecer serviços de saúde gratuitos ao conjunto da população.

Argumentava-se que a pressão sobre a demanda por serviços assistenciais, produzida pela rápida transição demográfica e epidemiológica em curso em alguns países ditos em desenvolvimento (e o Brasil era tido como um caso paradigmático), aliada às dificuldades de se elevar os recursos públicos destinados à saúde, decorrentes em grande parte (e isso o documento não explicitava) das políticas econômicas que exigiam ajustes estruturais com reduções nos gastos públicos, terminariam por inviabilizar políticas baseadas naquela concepção universalista. Considerando-se as restrições ao financiamento, argumentavase, ainda, que seria melhor que os governos abandonassem a perspectiva universalista na saúde.

A trajetória do movimento de luta por uma reforma sanitária seguiu um rumo radicalmente oposto àquelas recomendações. Pouco depois da publicação do documento do Banco Mundial, o Brasil consagrava no texto constitucional exatamente aquela concepção universalista. Com efeito, reconhecia-se que a saúde é direito de todos, direito que deve ser garantido tanto através de políticas capazes de reduzir os riscos à saúde, como através de políticas capazes de propiciar o acesso universal e igualitário às ações e aos serviços de saúde necessários à sua promoção, prevenção ou recuperação. Para garantir estes direitos, a Constituição de 1988 instituiu o Sistema Único de Saúde (SUS), pautado pelos princípios de descentralização, participação popular e integralidade.

A posição brasileira supõe a defesa de certos valores, dos quais um dos mais fundamentais pode ser resumido pela seguinte afirmativa: não julgamos justo que alguém seja privado de uma ação ou de um serviço de saúde do qual necessite, quer voltado à prevenção, quer à assistência, pelo simples fato de não ter como pagar por ele. Tal posição implica uma postura de solidariedade social, que se expressa em um arranjo para o financiamento público de ações e serviços de saúde que seja capaz de assegurar o volume de recursos necessários à viabilidade do SUS. Em outros termos, o grande desafio é o de aprimorar os dispositivos de financiamento do SUS de modo que o volume de recursos e as formas de sua alocação sejam compatíveis com o princípio de acesso universal e igualitário às ações e aos serviços de saúde em todos os níveis do sistema.

$\mathrm{O}$ argumento do Banco Mundial traz, entretanto, uma importante lição: se não queremos abandonar a defesa dos valores implícitos na proposta do SUS prevista no texto constitucional, devemos superar o desafio de construir dispositivos para o financiamento público do SUS, de forma a assegurar sua viabilidade e sustentabilidade. 
Segundo o texto constitucional, a saúde, juntamente com a previdência e a assistência social, integraria a seguridade social, que teria um orçamento conjunto, com receitas advindas das contribuições previdenciárias e das chamadas contribuições sociais. Em um primeiro momento, uma parte da receita previdenciária seria destinada à saúde. Isso não era surpreendente, haja vista a importância que os recursos do Instituto Nacional de Assistência Médica da Previdência Social (Inamps) tinham no financiamento da assistência médica no Brasil até então. No entanto, o orçamento da seguridade social nunca foi implantado e, em 1993, a própria idéia de seguridade social foi posta em xeque pela decisão unilateral do Ministério da Previdência Social de interromper o repasse de recursos previdenciários para o SUS.

A descontinuidade abriu uma crise no financiamento, pois desde as "Ações Integradas de Saúde" a cobertura dos serviços de saúde vinha sendo ampliada, em grande parte pelos recursos do Inamps. Então, duas estratégias foram postas em marcha para dar sustentação ao SUS. De um lado, buscaramse fontes alternativas de modo a evitar um colapso do sistema: a criação da Contribuição Provisória sobre Movimentação Financeira (CPMF), que teve o envolvimento direto do Ministério da Saúde, foi a expressão mais visível dessa primeira estratégia. De outro lado, travou-se um debate político com o intuito de modificar a Constituição de forma a assegurar um arranjo financeiro mais estável ao SUS. A emenda constitucional 29 pode ser vista como o produto dessa segunda estratégia.

A emenda estabelece a importância do financiamento do SUS pelos três níveis de governo, fixando percentuais mínimos da receita de estados e municípios que devem ser destinados à saúde. Em relação aos recursos federais, a emenda fixa um patamar mínimo para 2000 (pelo menos 5\% superior aos valores de 1999), que deveria ser mantido, sendo fixado como um percentual do Produto Interno Bruto (PIB).

A emenda 29, se integralmente cumprida, eleva o volume total de recursos destinados à saúde e, possivelmente, aumenta a participação relativa de estados e municípios no custeio do SUS. Penso, contudo, que sua maior importância é definir prazos e arenas de discussão sobre os ajustes nos dispositivos de financiamento público da saúde. Prevê-se que, em 2004, será aprovada uma lei complementar que estabelecerá novas regras, em um processo que, esperamos, seja de consolidação gradual da sustentação do SUS. Portanto, as revisões do financiamento do SUS se processarão no âmbito do legislativo nacional — que, segundo a agenda governamental, também apreciará propostas de reforma fiscal.

Exatamente por isso, consideramos mais do que oportuno discutir alguns pontos ligados ao financiamento do SUS. Gostaria de dar uma modesta contribuição ao debate, abordando algumas questões.

A primeira diz respeito à definição do volume total de recursos necessários ao SUS. Seriam os recursos atuais de fato suficientes? Ou deveriam as dis- 
cussões da reforma tributária e da futura lei complementar se pautarem pela perspectiva de elevações graduais no montante de recursos destinados ao SUS?

Não dispomos de critérios objetivos para estabelecer o volume total de recursos necessários a um sistema de saúde que garanta o acesso universal e igualitário às ações e aos serviços de saúde. A proposta da Constituição brasileira está entre as mais abrangentes do mundo. Contudo, segundo dados da Organização Mundial da Saúde (World Health Organization, 2002), o Brasil ocupava em 2000 o sexagésimo sétimo lugar em termos de gastos governamentais per capita entre os 191 países membros.

Se tomarmos o gasto governamental na saúde expresso como percentual do PIB, que pode ser visto como um indicador do peso do gasto público em saúde para o conjunto da economia (ou do esforço da economia comprometido com a garantia de certos direitos à saúde), a posição brasileira cai para o octogésimo terceiro lugar entre os mesmos 191 países.

Mas não devemos confiar tanto nas comparações internacionais. Talvez um ponto de partida mais adequado ao exame dessa questão seja indagar se, com o volume atual de gasto público em saúde, estamos garantindo o acesso universal e igualitário. Apesar dos grandes avanços, infelizmente a resposta é negativa. Parte significativa da população ainda está privada do acesso aos serviços de saúde de que necessita. Por exemplo, em 2000, cerca de 78 mil brasileiros morreram sem assistência médica. Na Região Nordeste, esses óbitos sem assistência médica corresponderam a cerca de $22 \%$ dos ocorridos em 2000.

Um outro exemplo: ainda na Região Nordeste, cerca de $23 \%$ das mulheres que tiveram filhos em 2000 se submeteram a menos de que quatro consultas no seu pré-natal. Poderíamos nos estender lembrando as filas e as dificuldades de acesso à média e alta complexidade... Contudo, os exemplos anteriores já indicam a necessidade de ampliação da cobertura das ações e dos serviços de saúde financiados publicamente, o que dificilmente se fará sem elevação do gasto público em saúde.

É verdade que com o Programa de Saúde da Família (PSF) temos assistido a uma grande expansão da cobertura da atenção básica, feita na perspectiva de implantação de um novo modelo assistencial. A expectativa de muitos é que tal modelo resultará em uma reordenação da demanda por serviços assistenciais nos demais níveis de atenção. Contudo, têm sido freqüentes entre os profissionais que atuam nas equipes do PSF as queixas sobre as dificuldades de garantir o acesso a esses demais níveis de atenção. Talvez essa dificuldade reflita, em muitas localidades, uma oferta insuficiente para o perfil epidemiológico da população, o que de novo nos remete a uma perspectiva de que a elevação do gasto público em saúde é desejável.

De fato, estamos com bases muito precárias para um exame mais detalhado da questão do montante de recursos necessários ao SUS. Penso que isso 
ocorre devido às práticas vigentes de programação da alocação de recursos federais nos serviços de saúde. A distribuição dos recursos federais em parte é feita por valores per capita (a parte voltada para a atenção básica ampliada), e em parte segue parâmetros calculados a partir da série histórica de produção. A utilização de série histórica tende a preservar o padrão da oferta de serviços de saúde vigente, estando completamente dissociada de qualquer percepção das necessidades da população. Mas o mais grave: os procedimentos operacionais terminam por silenciar a demanda reprimida e, portanto, todos os possíveis indicadores das desigualdades no acesso.

Não temos informações sobre quantos brasileiros tentam sem sucesso ser atendidos em suas necessidades, nem tampouco dispomos de parâmetros que indiquem o tempo gasto para que tal acesso se concretize. O debate entre gestores se faz predominantemente em relação à distribuição dos recursos federais, cujo montante final é dado. Gestores e instâncias de controle social vêemse privados do fundamental: a possibilidade de questionar os parâmetros que reproduzem a insuficiência e a chance de demandar, politicamente, a elevação de recursos que se justifiquem pela necessidade de superar eventuais insuficiências. Como demonstra Bonfim (2002), esses parâmetros mais servem a um racionamento que rompe com os princípios do SUS - e demole sua legitimidade social — do que à construção do SUS.

É claro, e é importante que se diga, que, em algumas localidades, foi possível aumentar dramaticamente o acesso aos serviços assistenciais necessários em todos os níveis de atenção sem ampliar significativamente o volume de recursos. Mas tais experiências estiveram associadas, até aonde sei, à existência prévia de grandes distorções (fraudes e uso desnecessário de procedimentos de alta complexidade) que, superadas, produziram um "excedente" de recursos. Esse "excedente" serviu como uma "janela de oportunidade" e pôde ser utilizado na ampliação efetiva do acesso. Mas essas especificidades não se reproduzem necessariamente em todos os lugares, de forma que tais experiências não nos levam a deixar de ter como perspectiva a elevação dos gastos públicos com o SUS.

Uma segunda questão diz respeito aos repasses de recursos entre os diversos níveis de governo. A questão tem se colocado no centro do debate em função da predominância do governo federal no financiamento do SUS. É claro que a questão só se coloca porque parte significativa dos recursos destinados à saúde é arrecadada pelo governo federal, mas é gasta sob a gestão de governos municipais ou estaduais.

Diante desse quadro, alguém poderia pensar que uma reforma tributária que possibilitasse descentralizar a arrecadação dos recursos destinados à saúde seria interessante. Penso, contudo, que a continuidade dos repasses de recursos federais aos demais níveis de governo, assim como a ampliação de repasses de recursos estaduais para o nível municipal, são importantes instru- 
mentos para as políticas de saúde voltadas à consolidação do SUS. Elas possibilitam, por exemplo, ações de promoção da igualdade inter-regional e intermunicipal e podem ser úteis no sentido de articular - e coordenar - os diversos níveis de governo.

O princípio constitucional da igualdade no acesso de todos aos serviços de saúde impõe um esforço de superação das desigualdades regionais e locais. Repassar mais recursos às localidades menos favorecidas pode ser uma forma de atenuar as desigualdades. Isso vem sendo experimentado através de, pelo menos, duas maneiras distintas, não necessariamente excludentes. O Ministério da Saúde, por exemplo, definiu como um de seus objetivos reduzir as diferenças dos repasses de recursos federais per capita entre estados e regiões.

O governo passado de fato produziu inegável redução das diferenças, sobretudo no que diz respeito às transferências per capita destinadas à alta complexidade. Entretanto, tomar a transferência per capita como indicador da igualdade é insuficiente. De um lado, não leva em conta os recursos municipais e estaduais alocados em benefício de uma população. Seria melhor buscar formas de repasse que contribuíssem para igualdades no total de gastos públicos em saúde per capita. Ou, como podem existir variações no perfil epidemiológico das diferentes regiões ou localidades, encontrar formas de repasse que assegurassem que as diferenças nos gastos públicos per capita fossem devidas exclusivamente aos diversos perfis de morbi-mortalidade de cada estado.

Outro modo de reduzir a desigualdade regional é estabelecer critérios que vinculem certos repasses aos valores de determinados indicadores que refletem as condições de saúde da população. Por exemplo, pode-se buscar formas de repasses que favoreçam com mais recursos localidades que têm apresentado piores indicadores sociais (como maiores mortalidades infantis). O estado do Rio Grande do Sul, por exemplo, adotou procedimentos desse tipo para distribuir recursos estaduais aos municípios.

De qualquer modo, quer o repasse de recursos de uma instância governamental para outra seja pautado por indicadores relativos aos gastos públicos alocados em cada região, quer por indicadores de saúde que de certa maneira expressam as maiores carências, o repasse de recursos entre os níveis de governo pode se transformar em importante instrumento de redução de desigualdades.

Uma segunda função política dos repasses diz respeito ao poder indutor de políticas dos demais níveis. O poder indutor se realiza quando se estabelecem condições para a concretização do repasse ou de parte dele. Trata-se de um poderoso instrumento de políticas, que, de fato, tem sido largamente utilizado pelo governo federal. Mas há que se atentar para o seguinte: as condições estabelecidas por um governo para o repasse de recursos públicos voltados para a saúde a um outro nível de governo refletem um posicionamento político e não favorecem, necessariamente, a consolidação do SUS conforme seus princípios. 
Há, por exemplo, condições que se referem a que ações devem ser implantadas pelos gestores municipais e como elas devem ser executadas. Tais normas operacionais são freqüentemente vistas nos manuais: define-se como deve ser a equipe do PSF, como deve se fazer o controle da tuberculose, como deve ser executada a distribuição de leite e óleo para crianças desnutridas etc. A condição para o repasse parece ser o cumprimento (admitidas algumas margens pequenas de variação) do estabelecido como sendo o melhor para todo o Brasil. Tal tipo de condicionalidade normalmente se associa a formas específicas de prestação de contas voltadas para o órgão que repassa os recursos (ou melhor, ao setor que elaborou as diretrizes específicas).

Essa modalidade de incentivo ou indução de políticas apresenta a vantagem de contribuir para a implantação de programas e ações específicas, mesmo em municípios cujos gestores têm baixa capacidade de governo. No entanto, traz muitas desvantagens, como o baixo controle social na elaboração das normas técnicas, a excessiva centralização e a verticalização, que fragmenta o sistema no nível local. Além disso, tal indução não incentiva o desenvolvimento da capacidade de governo nem o controle social local.

Na realidade, quando aplicadas em municípios que lograram um desenvolvimento dessas duas dimensões, as condicionalidades freqüentemente conflitam com as prioridades e formas de organização dos serviços estabelecidas pelo gestor local. Ademais, a prestação de contas vinculada aos incentivos pode enfatizar os indicadores de processo (se as ações estão sendo feitas como deveriam ser) e não os de resultados (se os resultados obtidos estão de acordo com os esperados).

Mas existem outras formas de incentivar ou induzir políticas através do estabelecimento de condições para o repasse de recursos. É possível, por exemplo, condicionar o repasse não à adesão de um certo modelo ou uma diretriz, mas à capacidade e criatividade do gestor local em adaptar — ou desenvolver - modelos e propostas adequados a sua realidade ou ao desenvolvimento local de processos de controle social mais efetivos.

Em certo sentido, esse foi o tipo de indução da NOB 96 (Ministério da Saúde, 1997) para que gestores municipais assumissem plenamente a gestão do sistema municipal, mesmo que apenas no que diz respeito à atenção básica. Talvez tenha sido essa a forma de incentivo adotada pelo governo do Rio Grande do Sul na Municipalização Solidária, quando estabeleceu que os municípios que definissem prioridades para a saúde através de um processo de orçamento participativo receberiam uma determinada fração de recursos 2 .

Centrei-me, nesse debate, em duas questões e procurei defender duas teses. A primeira afirma a necessidade de viabilizarmos uma elevação progressiva dos gastos públicos totais em saúde, com a conseqüente elevação do esforço da sociedade e da economia no sustento do SUS. Nosso problema principal não deve ser o de construir o SUS possível dada a escassez de recursos, 
mas sim o de construir a viabilidade de um sistema que garanta o acesso universal e igualitário, e que se paute pelos princípios constitucionalmente estabelecidos.

A segunda tese afirma a importância dos repasses federais entre os níveis de governos, por vê-los como instrumentos para reduzir as desigualdades entre as regiões (ou mesmo entre municípios) e para incentivar (ou mesmo induzir) políticas que contribuam para consolidar o SUS. É importante valorizar o desenvolvimento da capacidade dos governos municipais de gerirem o SUS, assim como o controle social no nível de governo que efetua o gasto.

\section{Notas}

1 Professor-adjunto no Instituto de Medicina Social da Universidade do Estado do Rio de Janeiro (UERJ) e Doutor em Saúde Coletiva. <rubenm@uol.com.br>

2 Para um relato da experiência de gestão do governo do Rio Grande do Sul, vide Ferla e Geyer (2002).

\section{Referências}

BRASIL. 2000. Emenda constitucional 29, de 13 de setembro de 2000. Altera os artigos 34, 35, 156, 160, 167 e 198 da Constituição Federal e acrescenta artigo ao Ato das Disposições Constitucionais Transitórias para assegurar os recursos mínimos para o financiamento das ações e serviços públicos de saúde. Acesso: 15 jul. $2003<$ http://conselho.saude.gov.br/ docs/EC29.doc $>$

BONFIM, Regina. 2002. Programação e financiamento. Parâmetros para uma universalização ou para racionamento? $O$ caso da média complexidade. Dissertação de Mestrado, Rio de Janeiro: Instituto de Medicina Social/Universidade do Estado do Rio Janeiro.
FERLA, Alcindo Antonio; GEYER, Ligia Maria Correia. 2002. Descentralização da gestão e regionalização da atenção no Rio Grande do Sul: consolidando e avaliando o processo de descentralização do SUS. In: Experiências Inovadoras no SUS: relatos de experiências: gestão dos serviços de saúde. pp. 31-60, Brasília: Ministério da Saúde.

MINISTÉRIO DA SAÚDE. 1997. Norma Operacional Básica do Sistema Único de Saúde: NOB-SUS 96. Brasília, D.F.

WORLD BANK. 1987. Financing health services: an agenda for reform. Washington: World Bank.

WORLD HEALTH ORGANIZATION (WHO). 2002. The World Health Report 2002. Geneva: WHO. 


\section{O financiamento ao SUS e o ajuste macroeconômico 4}

No texto "Financiando o SUS: algumas questões para o debate", Ruben Mattos faz um instrutivo balanço dos principais dilemas para o financiamento ao setor saúde no Brasil em uma perspectiva essencialmente interna ao setor e com ênfase no Sistema Único de Saúde (SUS). A perspectiva desses comentários é menos discutir diretamente as afirmações de Mattos, mas desenvolver alguns argumentos adicionais que contribuam também para a compreensão do tema. São duas as questões fundamentais que abordo nesse comentário:

a) o papel da restrição macroeconômica sobre os gastos públicos, que pode ter afetado sensivelmente a capacidade de gastos na área de saúde na década de 1990;

b) a natureza das mudanças substantivas no padrão do financiamento do setor na mesma década, com efeitos colaterais na natureza da oferta de serviços de saúde na esfera do Sistema Único de Saúde (SUS).

Em relação ao primeiro ponto, quero assinalar a necessidade metodológica de se analisar o padrão de financiamento da atenção à saúde pelos governos brasileiros, considerando o contexto do ajuste macroeconômico da década de 1990. Definem-se como ajuste macroeconômico as decisões de política fiscal decorrentes das estratégias de estabilização monetária e abertura do mercado doméstico implementadas pelo Plano Real a partir de 1994.

A nova integração ao mercado global adotada no país produziu a liberação do comércio externo, a privatização de empresas estatais de serviços públicos e a estabilidade monetária por paridade cambial fixa. Essas mudanças geraram uma elevada dependência da economia brasileira em relação aos fluxos de investimento externo ao longo da década de 1990.

Uma hipótese a considerar é que o ajuste fiscal da década de 1990, conseqüência direta dessa macropolítica, limitou severamente a capacidade de financiamento governamental na atenção à saúde. Essa limitação gerou efeitos perversos, devido à ampliação da desigualdade social, visto que os grupos populacionais de menor renda - e maior risco - são os que se beneficiam com os gastos governamentais na saúde (IBGE, 2000). Esses gastos são destinados ao Sistema Único de Saúde.

As evidências empíricas desse processo permitem a seguinte descrição exploratória da vulnerabilidade macroeconômica do país. A maior exposição ao setor externo funcionou de modo favorável à estabilização monetária em curto espaço temporal: de 1994 a 1998. Nesse período, existiu uma alta disponibilidade de recursos no mercado internacional para investimentos nos mercados emergentes. Inicialmente, a estabilização foi obtida com baixo custo fiscal, se analisarmos as evidências sobre as despesas não financeiras do governo central brasileiro nesses anos. No período, apenas no ano de 
1994, foi exigida a realização de superávit primário. Nos demais anos, o governo central operou com elevada folga na realização da programação orçamentária.

A partir de 1999, esse cenário foi radicalmente alterado. A incerteza macroeconômica internacional daquele ano tornou extremamente desfavoráveis as condições de estabilização monetária com abertura comercial do país. As conseqüências macroeconômicas dessa mudança de cenário, geradas pelas decisões da estabilização monetária e abertura comercial, foram:

a) rápido aumento do déficit comercial;

b) crescente deterioração do balanço de pagamentos;

c) alta dependência dos investimentos externos em títulos públicos diante da situação desfavorável do setor externo, remuneradas com altas taxas de juros reais;

d) grande crescimento da relação dívida pública/PIB, principalmente a partir de 1999;

e) rígida implementação de disciplina fiscal para obtenção de superávit primário entre 1999 e 2003, como condição contratual e garantia para fluxo de investimentos externos.

A escassez repentina de investimentos externos obrigou o país a aumentar o prêmio aos investidores em títulos públicos do governo central, bem como a estabelecer novas rodadas de negociação com o Fundo Monetário Internacional (FMI) e outras organizações internacionais para obtenção de recursos adicionais a fim de manter as reservas monetárias e cumprir os contratos comerciais e financeiros.

Os acordos internacionais de 1999 transformaram o compromisso com metas de superávit primário no avalista da capacidade da economia brasileira em remunerar investidores internos e externos em títulos públicos brasileiros. A disciplina fiscal tornou-se o principal fundamento da decisão pública no país, reduzindo os graus de liberdade das coalizões políticas quaisquer que tenham sido - em promover mudanças relevantes nas despesas com o setor social em curto prazo.

As evidências reunidas nessa análise demonstram que os efeitos colaterais da política de estabilização monetária, com abertura comercial, estão associados à contenção dos gastos públicos na área social no Brasil, bem como à alteração substancial do escopo e abrangência dos programas de proteção social. É necessário considerar as evidências de que as despesas sociais foram limitadas no seu crescimento se comparadas ao rápido crescimento das despesas financeiras do governo central, especialmente a partir de 19995. Nesse contexto, as despesas do setor saúde do governo federal foram estabilizadas entre 1994 e 2002.

Em relação ao segundo ponto - as mudanças substantivas na natureza do financiamento do setor na mesma década, com efeitos colaterais na natu- 
reza da oferta de serviços de saúde na esfera do SUS - existem evidências de que a estabilidade econômica pode ter provocado importantes mudanças na configuração do sistema de proteção na área de saúde como resultado das limitações impostas à disponibilidade de financiamento do setor público.

Examinemos como efetivamente o setor saúde respondeu às exigências de ajuste macroeconômico nas despesas públicas vis-à-vis a atraente agenda da descentralização federativa destacada por Mattos. Essa análise será realizada sob o ponto de vista do comportamento das despesas federais com a atenção à saúde entre 1994 e 2002, com especial ênfase no período de 1998 a 2002, em razão da disponibilidade pública de informações.

As estratégias substitutivas redefiniram o perfil das despesas do governo federal com a função saúde no Brasil. Verificou-se, ao longo da década de 1990, um expressivo crescimento da atenção básica ambulatorial em relação à atenção hospitalar e à atenção ambulatorial de média e alta complexidade (não-básica). Sob o ponto de vista da mudança do modelo assistencial, os objetivos desse processo substitutivo na oferta de atenção à saúde foram:

a) melhorar as condições de acesso e utilização de atenção à saúde pelo incentivo da oferta de serviços ambulatoriais em detrimento da oferta de serviços hospitalares;

b) mudar o perfil das despesas pela introdução de práticas preventivas e de serviços substitutivos de menor custo;

c) inserir a oferta de serviços no território pela responsabilização com os espaços e condições que compõem a vida cotidiana dos pacientes;

d) gerar um círculo virtuoso do gasto em saúde pela multiplicação de ações de prevenção e promoção à saúde.

Esta estratégia de mudança de modelo assistencial favoreceria à diversificação das estratégias de intervenção pela combinação de três tipos de ações: a promoção à saúde e redução de danos; a prevenção a enfermidades e acidentes; e a atenção curativa de nível ambulatorial de baixa complexidade. A desospitalização foi uma das peças centrais nesse processo de diversificação estratégica, como demonstraremos adiante.

É nesse contexto que o Piso Assistencial Básico (PAB) — criado através da Portaria GM/MS no 1882, de 18/12/1997 (Ministério da Saúde, 1997), e em vigor desde fevereiro de 1998 - constitui-se na medida decisiva de incentivo à expansão da rede básica de serviços de saúde em bases municipais. A política de incentivo federal assegurou aos municípios um valor per capita de $\mathrm{R} \$ 10,00$, repassado pelo governo federal, destinado exclusivamente ao custeio de um elenco específico de procedimentos.

A implementação do PAB e dos programas a ele associados, como o Programa de Saúde da Família (PSF), trouxe como principal inovação a chamada transferência regular e automática, em que o repasse federal é feito diretamente aos municípios. A condição de habilitação ao PAB é definida pela 
NOB/96 e obriga a criação de um Fundo Municipal de Saúde e de um Conselho Municipal de Saúde, dando maior autonomia e responsabilidade ao gestor municipal.

O PAB trouxe importantes inovações. Os novos mecanismos de transferência de recursos federais dissociaram a produção do faturamento, característica central do sistema de financiamento da atenção ambulatorial básica anterior. O sistema de pagamento por serviços prestados era desfavorável aos municípios com menor capacidade instalada, portanto, sem uma oferta adequada de unidades e de estabelecimentos de saúde. Comparados aos municípios de maior capacidade instalada, recebiam do SUS valores menores, porém coerentes, por um lado, com a baixa oferta da rede de saúde local, e por outro, com a quantidade de procedimentos e atendimentos realizados.

Quanto maior o número de hospitais, ambulatórios e postos de saúde, maior era a possibilidade de o município receber reembolsos financeiros do governo federal pela produção de serviços ao SUS. O antigo sistema, por meio do faturamento sobre o número de doentes e de procedimentos realizados, reproduzia também o modelo de atenção distorcido, com pouca ênfase na adoção de medidas preventivas e de promoção à saúde.

Um estudo exploratório realizado pelo Ministério da Saúde em 1997, baseado em dados do SIA/SUS (Ministério da Saúde, 1998) para o ano de 1996, revelou que aproximadamente 70\% dos municípios brasileiros (mais ou menos 3.860) receberam, naquele ano, menos de R $\$ 10,00$ per capita. Esse dado permite formular a hipótese de que os recursos do PAB, chegando diretamente aos municípios de menor capacidade instalada, com maior déficit de atendimento e rede de serviços de menor complexidade, provocariam um forte impacto distributivo na oferta de assistência ambulatorial básica, promovendo uma substituição de modelo assistencial e a diminuição na oferta de outras funções da atenção à saúde.

Evidencia-se que o processo de descentralização no período mencionado teve característica redistributiva dos recursos para a atenção básica, favorecendo os municípios de pequeno porte e reduzindo as diferenças regionais em relação ao financiamento federal para essa função da atenção ambulatorial básica à saúde.

O coeficiente de variação da destinação de recursos para os municípios tornou-se bastante homogêneo entre as regiões do país após a implantação do PAB, com destaque para as regiões Norte e Nordeste. A diminuição da dispersão relativa do total de recursos destinados à atenção básica, no período antes e depois da implantação do $\mathrm{PAB}$, em todas as regiões do Brasil, demonstra o impacto redistributivo do $\mathrm{PAB}$, com valores médios em torno de $\mathrm{R} \$ 10$ per capita/ano (Tabela 1 ).

Há evidências de que a ampliação da atenção ambulatorial básica com a perspectiva redistributiva causou também importantes mudanças na rela- 
Coeficiente de variação do total de recursos destinados à atenção básica nos municípios brasileiros Brasil 1997 x 1999

\begin{tabular}{lll}
\hline Grandes Regiões & 1997 & 1999 \\
\hline Norte & $98,4 \%$ & $16,7 \%$ \\
Nordeste & $79,6 \%$ & $18,0 \%$ \\
Sudeste & $59,1 \%$ & $21,0 \%$ \\
Sul & $81,0 \%$ & $23,5 \%$ \\
Centro-Oeste & $73,9 \%$ & $23,7 \%$ \\
Brasil & $74,8 \%$ & $20,8 \%$ \\
\hline
\end{tabular}

Fonte: Datasus/MS, 2000

ção da atenção hospitalar e de média e alta complexidade vis-à-vis a atenção ambulatorial básica. Considerando as informações publicadas por Ferrato (2002) e Souza (2002), resumidas na Tabela 2, é possível verificar que, em 1995, a proporção das despesas destinadas ao conjunto de atividades da atenção ambulatorial básica era de $23,5 \%$ do total das despesas hospitalares e dos gastos com a atenção ambulatorial de média e alta complexidade do governo federal (não-básicas). Em 2002, o crescimento das despesas ambulatoriais básicas chegou a 39,1\%.

Pelos dados do Datasus (Ministério da Saúde, 2003), nota-se que esse crescimento do custeio para a oferta de atenção básica foi combinado com a transferência de parcela importante dos recursos financeiros para os governos municipal e estadual. Entre 1998 e 2002, a gestão financeira dos recursos da atenção básica foi totalmente municipal e estadual. No mesmo período, a proporção de recursos de custeio da atenção hospitalar, de média e alta complexidade e das demais ações de saúde sob gestão financeira direta municipal e estadual passou de $36 \%$ para $69,3 \%$ dos recursos federais (Tabela 3).

Essa mudança de titularidade fortaleceu a oferta de atenção ambulatorial básica. Os dados sobre o PSF são muito expressivos. Entre 1998 e 2002, as equipes de saúde da família cresceram de 3.083 para 15.201 equipes. O total de população coberta passou de 10 milhões e seiscentos mil para 50 milhões e trezentos mil habitantes e a proporção de população coberta pelo PSF transitou de $6,5 \%$ para $25,2 \%$ do total da população brasileira (Souza, 2002).

É importante detalhar as características do financiamento do custeio dessa ampliação de atividades e cobertura de atenção ambulatorial básica, tomando como exemplo, primeiramente, a análise das informações públicas do Ministério da Saúde sobre as despesas específicas destinadas ao desenvolvimento do PSF entre 1998-2002. Analisando-se os dados contidos na 
Tabela 2

Relação entre despesa básica e despesa hospitalar e média complexidade Brasil 1995-2002

\begin{tabular}{lc}
\hline Ano & Razão Básica/Não-Básica \\
\hline 1995 & 0.23 \\
1996 & 0.20 \\
1997 & 0.25 \\
1998 & 0.31 \\
1999 & 0.33 \\
2000 & 0.33 \\
2001 & 0.35 \\
2002 & 0.39 \\
\hline
\end{tabular}

Fonte: Subsecretaria de Planejamento e Orçamento,

Ministério da Saúde. Apud Ferrato (2000) e Machado (2000).

Tabela 3

Proporção das despesas nominais do governo federal em atenção em saúde básica e não-básica* sob execução financeira de estados e municípios (em $\mathrm{R} \$$ milhão) Brasil 1998-1999

\begin{tabular}{lcc}
\hline Ano & Gasto Nominal & \% Execução Descentralizada \\
\hline 1998 & 8.833 & 36 \\
1999 & 10.905 & 54 \\
2000 & 12.417 & 61 \\
2001 & 14.436 & 66,7 \\
2002 & 15.671 & 69,3 \\
\hline
\end{tabular}

Fonte: Datasus/MS, 2003

* Excluindo despesas com os itens de despesa: custeio do MS e investimento,

pessoal, encargos sociais, dívida externa/interna e saneamento básico.

Tabela 4, pode-se concluir que o desenvolvimento do PSF no ano de 1998 foi feito com despesa média real anual por equipe de saúde da família extremamente baixa: em torno de $\mathrm{R} \$ 14.290,00$ anuais por equipe de saúde da família.

Diante do baixo ônus médio para o governo federal para a implementação do PSF, é explicável que as despesas médias anuais por equipe de saúde apresentassem, entre 2000 e 2002, um expressivo crescimento real de $15,3 \%$, revelando a importância estratégica do PSF na agenda da ampliação da atenção ambulatorial básica do país no período.

Na Tabela 4, as evidências sobre os custos adicionais de cada nova equipe de saúde são analisadas na coluna dos custos marginais. $\mathrm{O}$ ano de melhor eficiência marginal foi o de 2001, quando a incorporação de cada nova equipe de saúde ao sistema gerou a despesa adicional de apenas $\mathrm{R} \$ 37.950,00$, 
Despesa anual média real por Equipe de Saúde da Família (ESF)

Brasil 1998-2002

\begin{tabular}{lccc}
\hline Ano & Número de ESF & Despesa Média & Despesa Marginal \\
\hline 1998 & 3083 & $14.290,00$ & \\
1999 & 4254 & $23.713,00$ & $49.115,00$ \\
2000 & 8604 & $40.457,00$ & $57.128,00$ \\
2001 & 13168 & $39.382,00$ & $37.950,00$ \\
2002 & 15201 & $45.375,00$ & $95.177,00$ \\
\hline
\end{tabular}

Fonte: Datasus/MS, 2003

Deflator IPCA-IBGE. Em R\$1,00

ou seja, R\$ 3.162,00 mês ao SUS. Essa tendência a ganhos de escala em termos de despesas marginais reais para a criação de cada nova equipe de saúde da família foi caraterística do período de 1998 a 2001, indicando que o ônus para as despesas federais com a ampliação do número de equipes de saúde da família coberto pelo programa tornara-se extremamente baixo.

Em 2002, o desembolso marginal no PSF foi, de fato, ampliado: as despesas marginais por nova equipe de saúde acrescida ao PSF passaram dos R\$ $37.950,00$ para $\mathrm{R} \$ 95.177,00$. Um incremento real nas despesas marginais de $151 \%$

Uma outra dimensão do comportamento do financiamento da atenção básica, particularmente do PSF, pode ser visualizada quando examinadas as despesas médias e marginais por habitante coberto pelo programa. Como o programa propõe uma agenda proativa da ampliação de atividades abrangentes de promoção à saúde e redução de danos à saúde, com o objetivo de gerar bem público e externalidades positivas com a atenção sanitária, podese concluir que a população coberta pelo PSF confunde-se com a população que utiliza suas atividades ou é beneficiária da oferta de seus serviços.

Considerando que a relação equipe de saúde é uma constante, ou seja, cada equipe oferece a cobertura para 3.450 pessoas, pode-se examinar a qualidade das despesas do governo federal com o aumento da oferta de atenção do PSF por habitante. Como demonstrado na Tabela 5, as despesas médias reais por habitante mês do PAB variaram, no período, do valor mínimo de $\mathrm{R} \$ 0,33$ em 1998, para o valor máximo de R\$ 1,10, em 2002. O PSF pôde oferecer, entre 1998 e 2002, cobertura de atenção à saúde com despesas reais mensais médias ao SUS de R\$ 0,77 por habitante.

Os dados de variação das "despesas marginais" para cada novo habitante do país incluído na cobertura do PSF revelam também a grande eficiência econômica do programa: entre 1998 e 2002, cada novo habitante coberto pelo programa gerou uma despesa média real de R\$ 1,46/mês! Esse valor 
Despesa mensal média real por habitante com cobertura do PSF Brasil 1998-2002

\begin{tabular}{lccc}
\hline Ano & Número de ESF & Despesa Média & Despesa Marginal \\
\hline 1998 & 3083 & 0,33 & \\
1999 & 4254 & 0,57 & 1,21 \\
2000 & 8604 & 0,93 & 1,41 \\
2001 & 13168 & 0,93 & 0,93 \\
2002 & 15201 & 1,10 & 2,31 \\
\hline
\end{tabular}

Fonte: Datasus/MS, 2003

Deflator IPCA-IBGE. Em R\$ 1,00

apresentou uma relevante oscilação para cima no ano de 2002, acompanhando as mudanças de destinação orçamentária já comentadas. De qualquer maneira, cada habitante incorporado ao PSF gerou na prática, em 2002, uma despesa adicional real de apenas $\mathrm{R} \$ 2,31 /$ mês.

Tais evidências indicam que os recursos federais destinados à ampliação de cobertura do PSF entre 1998-2002 foram extremamente baixos, considerando tanto a variação nos valores médios quanto nos valores marginais. Estes recursos foram efetivos no sentido da ampliação de cobertura e da adoção - pelos governos municipais e estaduais - de um novo modelo de oferta de serviços básicos baseado em equipes de saúde da família, principalmente entre os anos 2001 e 2002. Nesse período, pelos dados de variação das despesas marginais, os recursos destinados pelo governo federal ao PSF cresceram mais que o número de equipes de saúde da família.

As evidências disponibilizadas pelo Datasus (Ministério da Saúde, 2003) também permitem especular sobre os possíveis efeitos do incremento no custeio de atenção básica como um vetor de focalização do SUS na produção de serviços de saúde de baixa complexidade. A possibilidade da focalização levaria à conclusão de que as despesas com atenção ambulatorial básica teriam crescido com os demais insumos diretamente relacionados à atenção à saúde na perspectiva da integralidade — como atenção hospitalar e serviços de média e alta complexidade - sendo mantidos constantes, crescidos em menor proporção ou simplesmente reduzidos.

Os dados das Tabelas 6 e 7 permitem avançar nesse assunto. Analisando-os, pode-se concluir que o crescimento da atenção ambulatorial básica e do PSF no Brasil foi concomitante à diminuição do financiamento para a oferta de internação hospitalar. As despesas com média e alta complexidade também sofreram descontinuidade significativa quando relacionadas às despesas com atenção básica, ainda que em menor proporção entre os anos de 1998 e 2002 (Tabela 8). 


\section{Tabela 6}

Relação entre despesa PAB/despesa internação Brasil 1998-2002

\begin{tabular}{lc}
\hline Ano & Razão PAB/Internação \\
\hline 1998 & 0.54 \\
1999 & 0.85 \\
2000 & 1.28 \\
2001 & 1.61 \\
2002 & 1.80 \\
Incremento \% entre razões & $233 \%$ \\
em 1998 e 2002 & \\
\hline
\end{tabular}

Fonte: Datasus/MS, 2003

Tabela 7

Relação entre despesa PSF/despesa internação Brasil 1998-2002

\begin{tabular}{lc}
\hline Ano & Razão PSF/Internação \\
\hline 1998 & 0.018 \\
1999 & 0.039 \\
2000 & 0.15 \\
2001 & 0.25 \\
2002 & 0.35 \\
Incremento \% entre razões & $1.844 \%$ \\
em 1998 e 2002 & \\
\hline
\end{tabular}

Fonte: Datasus/MS, 2003

\section{Tabela 8}

Relação entre despesas PAB/despesa de média e alta complexidade Brasil 1998-2002

\begin{tabular}{lc}
\hline Ano & Razão PAB/Média e alta complexidade \\
\hline 1998 & 0.54 \\
1999 & 0.65 \\
2000 & 0.67 \\
2001 & 0.61 \\
2002 & 0.63 \\
Incremento \% entre razões & $17 \%$ \\
entre 1998-2002 & \\
\hline
\end{tabular}

Fonte: Datasus/MS, 2003 
A desospitalização e a baixa oferta de leitos hospitalares no SUS podem ter sido resultado direto dos pressupostos da estratégia de ampliação de cobertura ambulatorial. Uma análise adicional pode identificar os efeitos colaterais dessa orientação sobre a possível redução na oferta de leitos no SUS em estados e regiões do país, a ociosidade hospitalar e a saída dos segmentos privados do subsistema SUS.

Como se pode constatar observando-se a Tabela 9, dentro da atenção básica, os recursos federais para o PSF foram os que mais cresceram a partir de 2001. Esse crescimento dos recursos para o PSF pode ter favorecido a indução do PSF aos gestores locais, fortalecendo a tendência substitutiva dentro da própria atenção básica e permitindo a adoção, em larga escala, das equipes de saúde nos municípios. Os efeitos dessas mudanças sobre a configuração da oferta do SUS e os rumos do SUS em um contexto de restrição evidente do gasto público em saúde é que devem ser avaliados com precisão em novos estudos sobre a década de 1990.

Tabela 9

Relação entre despesa PSF/despesa PAB Brasil 1998-2002

\begin{tabular}{lc}
\hline Ano & Razão PSF/PAB \\
\hline 1998 & 0.033 \\
1999 & 0.045 \\
2000 & 0.122 \\
2001 & 0.154 \\
2002 & 0.195 \\
Incremento \% entre razões & $491 \%$ \\
em 1998 e 2002 & \\
\hline
\end{tabular}

Fonte: Datasus/MS, 2003 


\section{Notas}

3 Pesquisador titular da Escola Nacional de Saúde Pública (ENSP/Fiocruz) e professor assistente do Instituto de Saúde Comunitária da Universidade Federal Fluminense (UFF). Doutor em Planejamento pela Universidade de São Paulo (USP) e Mestre em Ciência Política pelo Instituto Universitário de Pesquisas do Rio de Janeiro (IUPERJ). Desenvolve pesquisa na área de política pública e financiamento na área social; avaliação de programas e políticas; reforma do Estado e governança organizacional no setor saúde, com ênfase no estudo sobre organizações hospitalares.<nilson@ensp.fiocruz.br>.

4 Texto realizado na pesquisa "Avaliação do Impacto e Custo do PAB", financiada pelo Projeto Economia da Saúde/Cooperação Reino Unido/Ministério da Saúde. Rio de Janeiro, Escola Nacional de Saúde Pública, abril 2002.

5 A competição por recursos entre as políticas sociais também limitou a capacidade de financiamento do setor governamental na saúde. Entre estas políticas, destaca-se o crescimento, por inércia, das despesas com previdência social pública e privada. Esse tema não é discutido nesse trabalho.

\section{Referências}

DRAIBE, Sérgio Antônio. 2002. Brasil - A proteção social após vinte anos de experimentação reformista. In: Taller Inter-Regional Protección Social en una Era Insegura: Un Intercambio Sur-Sur sobre Politicas Sociales Alternativas en Respuesta a la Globalización. Santiago, PNUD.

FERRATO, Gabriel. 2002. Financiamento e investimento em saúde pública de 1995 a 2002. In: O Sistema de Único de Saúde (Negri, Barjas e Vianna, Ana L., org.), pp. 391-410, São Paulo: Sobravime.
IBGE - Instituto Brasileiro de Geografia e Estatística. 2000. Acesso e Utilização de Serviços de Saúde 1998. Rio de Janeiro: IBGE.

MINISTÉRIO DA SAÚDE. 1997. Portaria GM/MS no 1882, de 18/12/1997.

MINISTÉRIO DA SAÚDE. 1998. Relatório do MS-GTT/PAB. Brasília: Ministério da Saúde.

SOUZA, H. M de. 2002. Saúde da Família: desafios e conquistas. In: O Sistema de Único de Saúde (Negri, Barjas e Vianna, Ana L., org.) pp. 202-220, São Paulo: Sobravime. 